\title{
USING SIMULATION FOR REDUCING RISK OF A MINING OPTIMIZATION PROJECT
}

\author{
Chinbat, U. \\ Graduate School of Economics and Business Administration, Furo-cho, Nagoya University, \\ Chikusa-ku, Nagoya, Aichi 464-8601, Japan \\ E-Mail: chinbat.undram@b.mbox.nagoya-u.ac.jp
}

\begin{abstract}
The use of simulation in a project management can illustrate visual display of the project objective and the process virtually but realistically. This paper investigates the valid benefits of using simulation technique for a Mining and Iron Production Factory (MIPF) project. It is believed by the author that mining activity is particularly subject to more risks than other business activities because of its uncertainty, complexity and high cost. One of the first things to consider before starting mining projects is the risk factor. Some project risks can be reduced by visualizing and understanding the process before the actual initiation process. The paper illustrated the advantages of using computer aided simulation for an optimization project of a MIPF in a real life case study.

(Received in February 2009, accepted in June 2009. This paper was with the author 1 month for 1 revision.)
\end{abstract}

Key Words: Project Risk Management, Mining Optimization, Simulation Analysis

\section{INTRODUCTION}

In a project context, risk is the chance of something happening that will have an impact upon objectives, including possibility of loss or gain, or variation from a desired or planned outcome, as a consequence of the uncertainty associated with following a particular course of action. The purpose of risk management is to minimize risks of project failure and to identify and take advantage of opportunities. In particular, risk management assists project managers in setting priorities, allocating resource and implementing actions and processes that reduce the risk of project failure [1].

A systematic identification, analysis and assessment of risk and dealing with the results contribute significantly to the success of projects. Risk should be considered at the earliest stages of project planning, and risk management activities should be continued throughout a project. Simulation analysis was introduced to a mining and iron production factory project to estimate performance and assess possible risks in a real life case.

Simulation is a process of designing a model of a real system and conducting experiments with this model for the purpose of understanding the behaviour of the system and/or evaluating various strategies for the operation of the system [2]. Computer designed simulation can help project management practitioners understand the behaviour of the system and optimize the system through various strategies in a virtual reality.

The use of simulation has shown great benefits in risk mitigation of an optimization project of a MIPF providing accurately calculated numeric data of the process. The numeric deliverables of the simulation analysis provided a discovery of the elements to be improved and an extent of the optimization project. 


\section{MINING PROJECT RISKS}

Mining projects are subject to high risks because their size, complexity and high cost. Unfortunately, very little research related to a particularly mining project risk has been conducted up to date. Most of the research related to mining project risks studied oil and petroleum well development projects.

Del Cano and de la Cruz [3] noted that RM becomes an integral part of project management and plays such an important role that its application goes beyond the traditional scope which normally centres on the construction phase. Williams [4] stated in his paper titled "A classified bibliography of recent research relating to project risk management", that the need to identify a project's uncertainties, estimate their impact, analyze their interactions and control them within a RM structure has only in recent years been realized, mainly within the defence, construction and oil industries. Thus, there is a need to integrate this work within a cohesive academic framework. However, the oil industry is an important user of RM, but as well as being notoriously secretive, their requirements are somewhat unusual as there is more empirical data about two main areas of uncertainty - weather and geology [4, 5, 6, 7].

The earliest literature found using simulation analysis in an oil project risk analysis was made by Hall [6] in 1986 in the North Sea oil project, where a Monte Carlo simulation tool was utilized in two projects to determine the probabilities of the project completion day. Risk analysis and management of petroleum exploration ventures is growing worldwide and many international petroleum companies have improved their exploration performance by using principles of risk analysis in combination with new technologies [8]. The use of the simulation technique in studies where the dynamics of the productive system has relative operational complexity, difficulty of modelling or cause upset to the users, can be applied and will reproduce with reasonable fidelity the reality of the scenery in subject [9].

The author has composed a risk ranking by the contribution weight of each risk to project failure using a questionnaire survey from the professionals working in the Mongolian mining industry. The findings of the survey were evaluated based on the probability of the risk occurrence and impact on project objectives once the risk event occurs. This is achieved by converting the descriptive assessments of the risk likelihoods and potential impacts into numerical values and plotting the risk probability-impact matrix, shown in Fig. 1. In this study we will approximate the risks' logic probability values and for the impact value will use the survey study developed by the author.

In the matrix, the x-axis represents the impact value while the y-axis represents the probability value. The risks plotted in the upper right corner of the matrix are the risks with high probability and high impact to project failure. The risks plotted in the lower right corner are the risks with low probability and high impact. Likewise, the risks in the upper left corner are the risks with high impact and low probability and the ones in lover left corner are the risks with low impact and low probability. For example, the risk from "owner's financial difficulties" has been plotted on the upper right corner, which is considered as the risk with highest probability and highest impact to project failure. Alternatively, the risk from "unpredicted environmental damages" has the lowest probability and a medium to high impact to project failure. Furthermore, the risk from "human/organizational resistance" has a low probability and low to medium impact on project failure.

Project managers should assess and evaluate potential risks according to their probability and impact to project failure and treat the risks accordingly.

In this study, an example of risk mitigation by using simulation analysis in a MIPF optimization project has been conducted in a real life case study. 


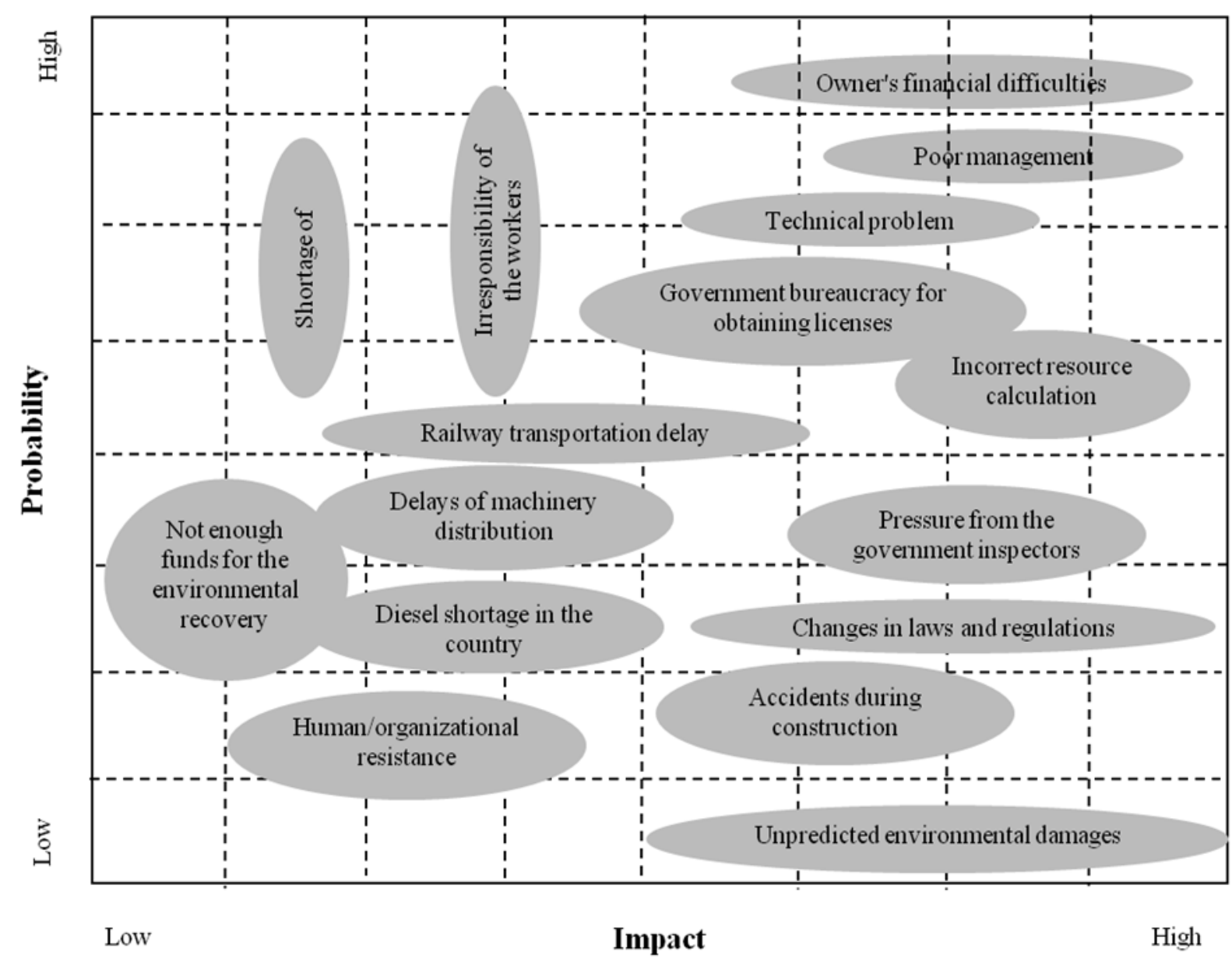

Figure 1: Probability-Impact Matrix.

\section{THE CASE STUDY}

Monzol is a Mongolian based company that currently holds exploration licenses for gold, coal, iron and poly-metal deposits in the territories of Selenge, Dornogobi, Dornod and Sukhbaatar provinces of Mongolia. The company's research and exploration work has discovered iron ore deposit - Ervei Khuder - in Ervei khoshuu district of Sukh-baatar province (approximately $320 \mathrm{~km}$ distance from the capital Ulaanbaatar). Currently, the company is operating an open mining and iron production factory and exporting its product to the Harbin Metallurgical Industry of China. Thus, the company has gained an actual experience in iron production and sales. Monzol is aiming to improve its current operation of the Ervei Khuder MIPF.

\subsection{The Ervei Khuder Mining an Iron Production Factory}

Ervei Khuder MIPF produces annually, 556 thousand tons of Iron Ore $\left(\mathrm{Fe}_{2} \mathrm{O}_{3}\right)$ which produces approximately 360 thousand ton of Iron (Fe) after being processed through the MIPF.

The objectives of the optimization project of the Ervei Khuder MIPF were decided by the team after interviewing with the geologists and engineers of MIPF, and the main problem at the Ervei Khuder was the process lead time (PLT). The MIPF was not operating at full capacity due to major bottlenecks and problematic production processes. Thus, the goal of the improvement project was the following: 
- to increase factory capacity,

- diminish the bottlenecks, and

- reduce the MIPF operating cost.

\subsection{Project Risks}

One of the major steps in project risk management is to identify and assess the potential risks in the project [10]. The case study was carried according to the project risk management process model which was developed by the author, as shown in Fig. 2.

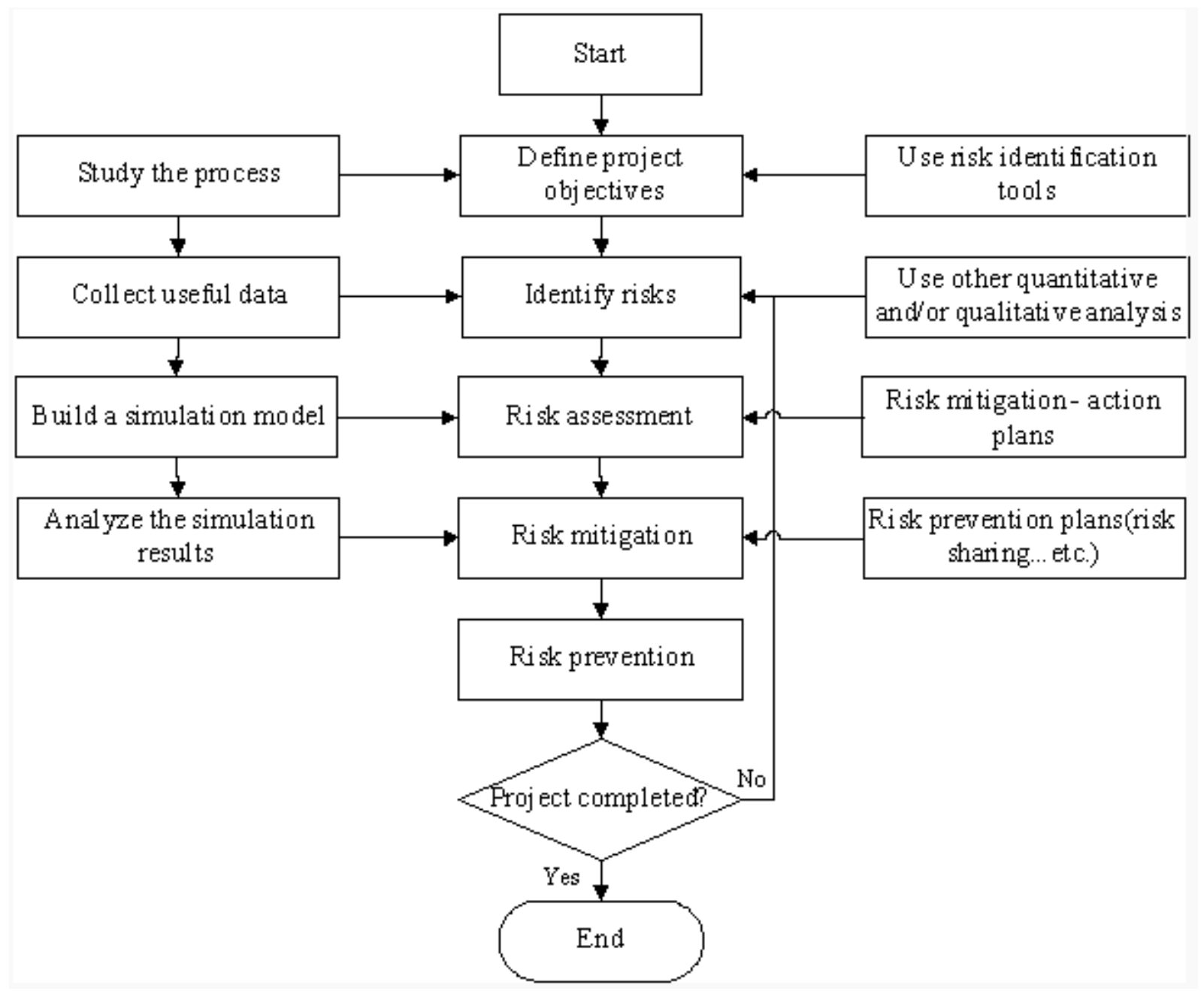

Figure 2: Project Risk Management Process Model.

The model can be described as follows:

- Identify risks: After defining the project objectives, the team identified possible risks, by studying the process and using various risk identification tools.

- Risk assessment: Once the process has been studied and the risks have been identified, useful data for building a simulation model are collected. The identified risks are assessed using suitable tools such as probability - impact matrix. Simulation modelling method can be useful for assessing certain risks, such as operational risks.

- Risk mitigation: The simulation model results were used to mitigate specific risks which were mentioned earlier. 
- Risk prevention: The results of the simulation analysis helped the team to avoid certain negative risks. At this point the team also needs to make risk prevention plans such as risk sharing for further risks.

- Finally, if the project is not completed, the process will start from the risk identification phase, because risks are uncertain and they need to be monitored and managed constantly.

Before considering any risks of a project, the project team must define its objectives. Based on the objectives, risks can be identified with risk identification methods such as brainstorming, literature review and questionnaire. In this research, study of the process was also essential to collect useful data for building simulation model. The simulation model was used to assess risk and the results were evidently a useful risk mitigation tool.

Project risk may cause by external factors, such as diesel shortage in Mongolia, or a railway transportation delay, as mentioned in the list of risk factors earlier. Mitigation of risks from these factors is complex and almost impossible to predict. However, internal factors can be identified and mitigated in the early stages of the project. The risks were considered and listed by the team as shown in Table I.

Table I: List of Risks Associated with the Optimization Project.

\begin{tabular}{|c|c|c|c|c|}
\hline $\begin{array}{l}\text { Risk } \\
\text { number }\end{array}$ & Risks & $\begin{array}{l}\text { Risk } \\
\text { effect }\end{array}$ & $\begin{array}{l}\text { Risk } \\
\text { probability }\end{array}$ & Risk mitigation method \\
\hline R-1 & Poor management & High & Low & $\begin{array}{l}\text { Receive management consultancy } \\
\text { from a firm with a good reputation } \\
\text { and experience. }\end{array}$ \\
\hline $\mathbf{R}-\mathbf{2}$ & Technical problem & High & Low & $\begin{array}{l}\text { Create check-list. } \\
\text { Prepare for any possible breakdowns, } \\
\text { so it can be fixed within the possible } \\
\text { minimum repair time. }\end{array}$ \\
\hline R-3 & $\begin{array}{l}\text { Irresponsibility of the } \\
\text { workers }\end{array}$ & High & Low & $\begin{array}{l}\text { To supervise the workers daily. } \\
\text { Educate the workers. } \\
\text { Motivate the workers. }\end{array}$ \\
\hline R-4 & $\begin{array}{l}\text { Railway transportation } \\
\text { delay }\end{array}$ & Low & Low & $\begin{array}{l}\text { To investigate railway demand before } \\
\text { shipping the machines. Chose not } \\
\text { busy periods for shipment. }\end{array}$ \\
\hline R-5 & $\begin{array}{l}\text { Delays of machinery } \\
\text { distribution }\end{array}$ & Low & High & $\begin{array}{l}\text { To make payment after shipment to } \\
\text { the machine supplier. }\end{array}$ \\
\hline R-6 & Environmental damages & High & Low & Insure the plant. \\
\hline $\mathbf{R}-7$ & $\begin{array}{l}\text { Human/organizational } \\
\text { resistance }\end{array}$ & Low & Low & $\begin{array}{l}\text { To organize weekly meetings with } \\
\text { the employees to discuss about } \\
\text { problems. }\end{array}$ \\
\hline $\mathbf{R - 8}$ & Accidents & High & Low & To follow the manuals. \\
\hline $\mathbf{R}-\mathbf{9}$ & $\begin{array}{l}\text { Uncertain optimization } \\
\text { elements }\end{array}$ & High & High & $\begin{array}{l}\text { Use simulation analysis to visualize } \\
\text { the process and find out the elements } \\
\text { that needs to be optimized. }\end{array}$ \\
\hline $\mathbf{R - 1 0}$ & $\begin{array}{l}\text { Uncertain optimization } \\
\text { indication }\end{array}$ & High & High & $\begin{array}{l}\text { Use simulation analysis to create } \\
\text { virtual optimization indicating } \\
\text { various optimization points. }\end{array}$ \\
\hline
\end{tabular}

The identified risks were analyzed and plotted in the probability and impact matrix with a risk mitigation contour as shown in Fig. 3.

The probability of risks can be estimated by identifying the major drivers of risk in the project. The consequence of risks usually comes down to the cost factor. Every consequence such as project delay, project failure will result in loss of money. 
Objective of the project risk management is to mitigate the probability and the consequences of the risks identified and considered as hazardous to project success. Author of this paper argues that, simulation can be an effective tool for risk mitigation.

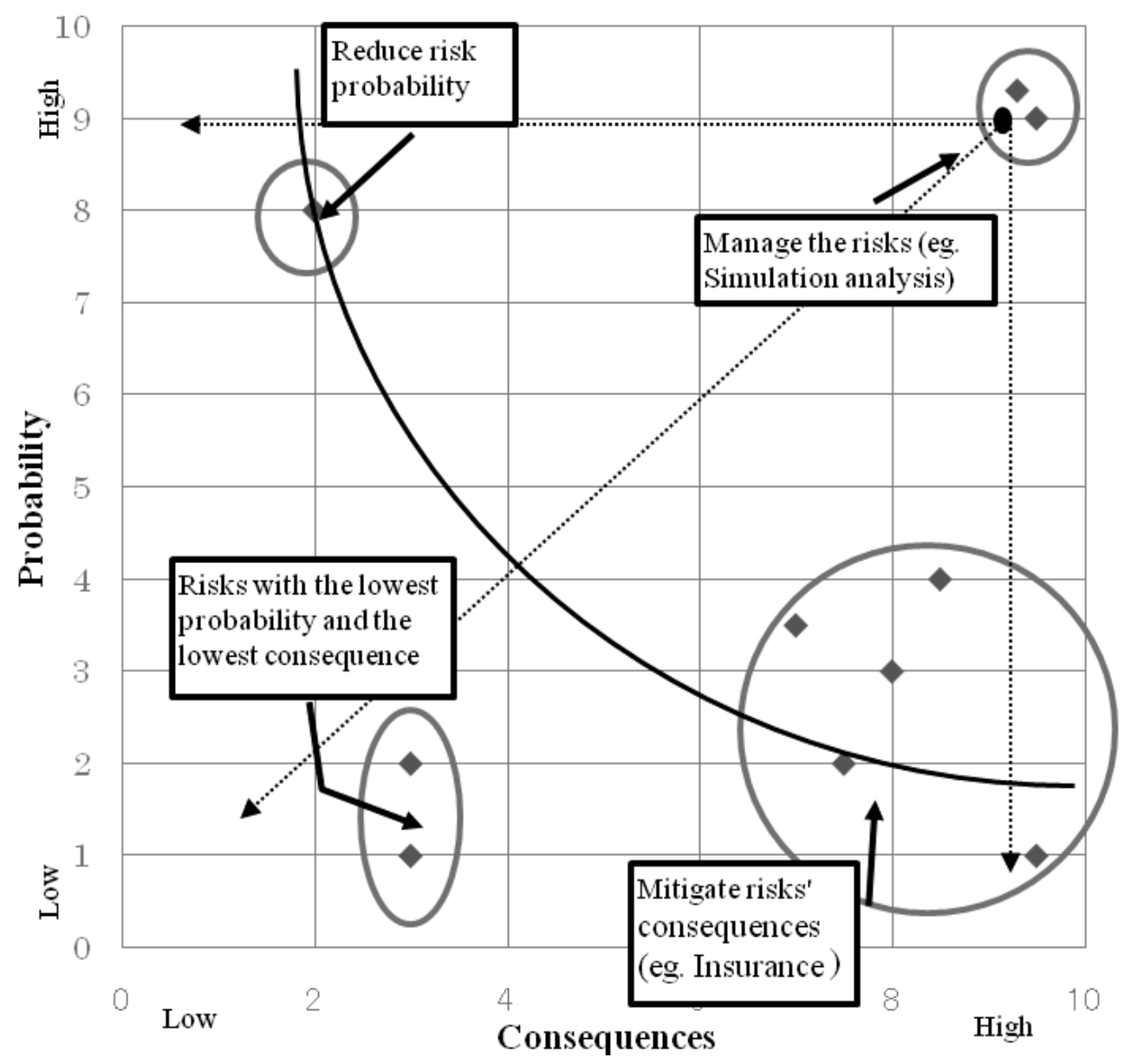

Figure 3: Risk mitigation contour.

\subsection{Simulation Analysis}

The company management has decided to endeavour Arena, a software package for process analysis and simulation [11], tool in their optimization project of the MIPF. When one experiments with a model to measure the possible future behaviour of a system (e.g., simulation), one gains insight into the nature of a system of a process, identifies problems with system design and manage risk by making decisions with a better understanding of the costs and benefits [12].

To understand the current system of the Ervei Khuder MIPF, a study of the real operation was conducted and a process map was drawn to illustrate the natural path of the process, as shown in Fig. 4.

Without a competent data, quantitative analysis techniques are worthless [13]. The key data information of the MIPF operation was collected through a time study and observation and was summarized on a developed spreadsheet, which is illustrated on Table II. The data was summarized using an Arena Input Analyzer to determine the probability distribution.

The MIPF operation process was visualized and investigated using the simulation analysis tool. The project team must establish valid and reliable metrics to help monitor their progress towards the project goals. 


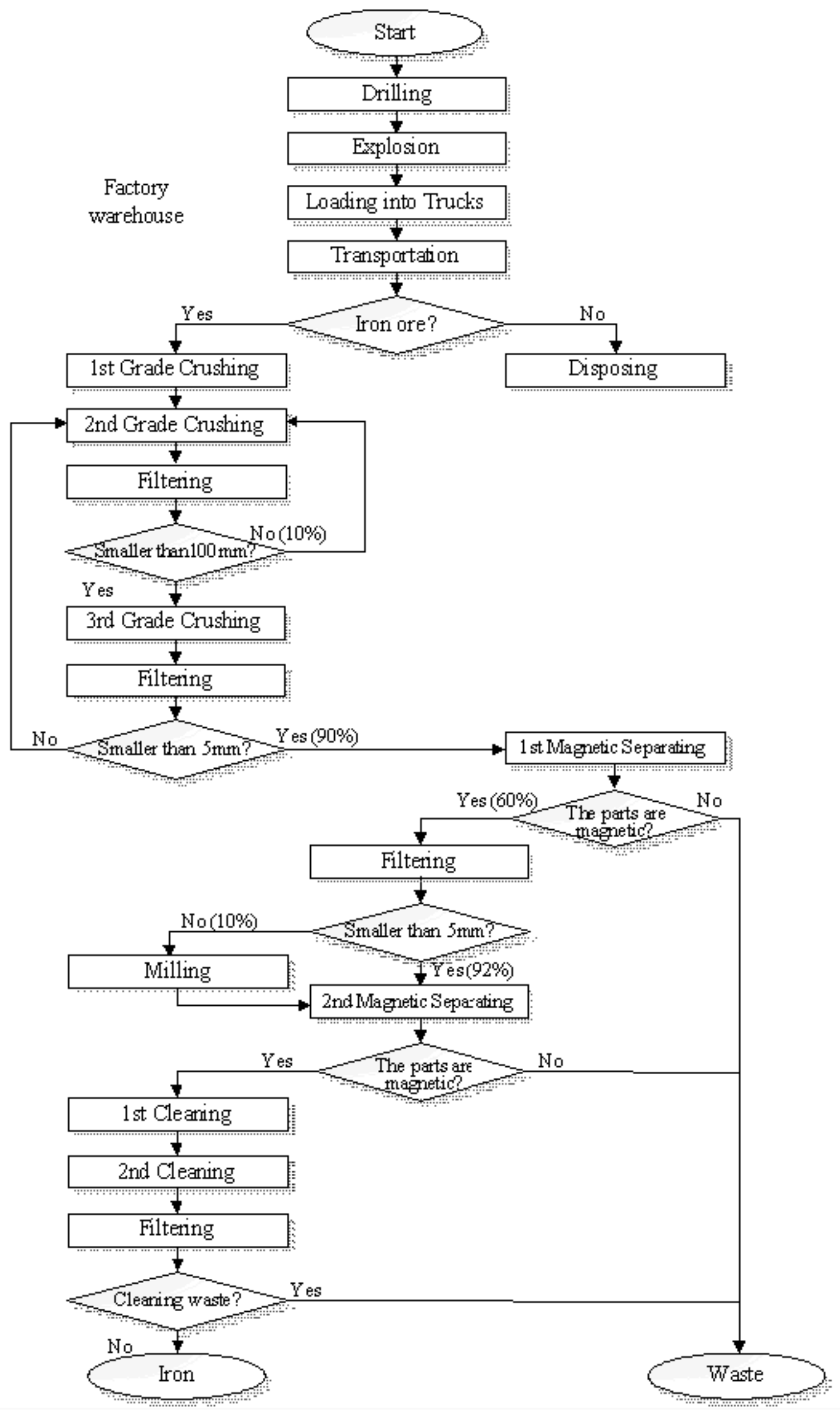

Figure 4: Process Map of the Iron Production Factory. 
Table II: List of Parameters of the Mining and Iron Production Factory.

\begin{tabular}{|c|c|c|c|}
\hline \multirow{2}{*}{ Parameter names } & \multirow{2}{*}{ Units } & \multicolumn{2}{|c|}{ Parameters } \\
\hline & & Soil & Ore \\
\hline Average pit hole depth & $\mathrm{m}$ & 11.7 & 11.9 \\
\hline Preparation and finish time of the driller & $\min$ & $\mathrm{EXPO}(6)$ & $\mathrm{EXPO}(6)$ \\
\hline Driller output per shift & $\mathrm{m}$ & EXPO(92.4) & EXPO(90.2) \\
\hline Drill time per 1 meter pit hole including the support time & $\min$ & 2.21 & 2.51 \\
\hline Explosion process time length & hours & \multicolumn{2}{|c|}{$\operatorname{UNIF}(2,3)$} \\
\hline Crusher speed for processing 1tn ore & $\min$ & - & $\operatorname{UNIF}(6,6.6)$ \\
\hline Filterer speed for processing 1 tn ore & $\min$ & - & UNIF(3.6, 4.2) \\
\hline Magnetic separator and miller speed for processing 1 tn ore & $\min$ & - & $\operatorname{EXPO}(7.2)$ \\
\hline Cleaner speed for processing 1tn ore & $\min$ & - & EXPO(6.6) \\
\hline Conveyor speed & $\mathrm{m} / \mathrm{sec}$ & $\overline{-}$ & 1.6 \\
\hline Conveyor length & $\mathrm{m}$ & - & $50,50,50,70$ \\
\hline Excavator process time to fill 25tn truck & $\min$ & $\operatorname{UNIF}(8,16)$ & $\operatorname{UNIF}(12.5,25)$ \\
\hline Bulldozer process time of 1tn & $\min$ & EXPO(5.25) & $\mathrm{EXPO}(10.25)$ \\
\hline Allowed truck speed within the plant & $\mathrm{km} / \mathrm{h}$ & & 30 \\
\hline Truck carrying capacity & $\operatorname{tn}$ & 16 & 25 \\
\hline \multicolumn{4}{|l|}{ Distance between stations } \\
\hline Starting point & \multicolumn{2}{|c|}{ Destination point } & Distance (m) \\
\hline Parking & \multicolumn{2}{|c|}{ Mining } & 1000 \\
\hline Mining & \multicolumn{2}{|c|}{ Disposal hill } & 1500 \\
\hline Mining & \multicolumn{2}{|c|}{ Factory } & 500 \\
\hline
\end{tabular}

The "as-is" model was developed to create a clearer view of the existing process, which provided a visual display and a numeric metrics of the process to help to identify and analyze the possible risks in the operation of MIPF as shown in Fig. 5.

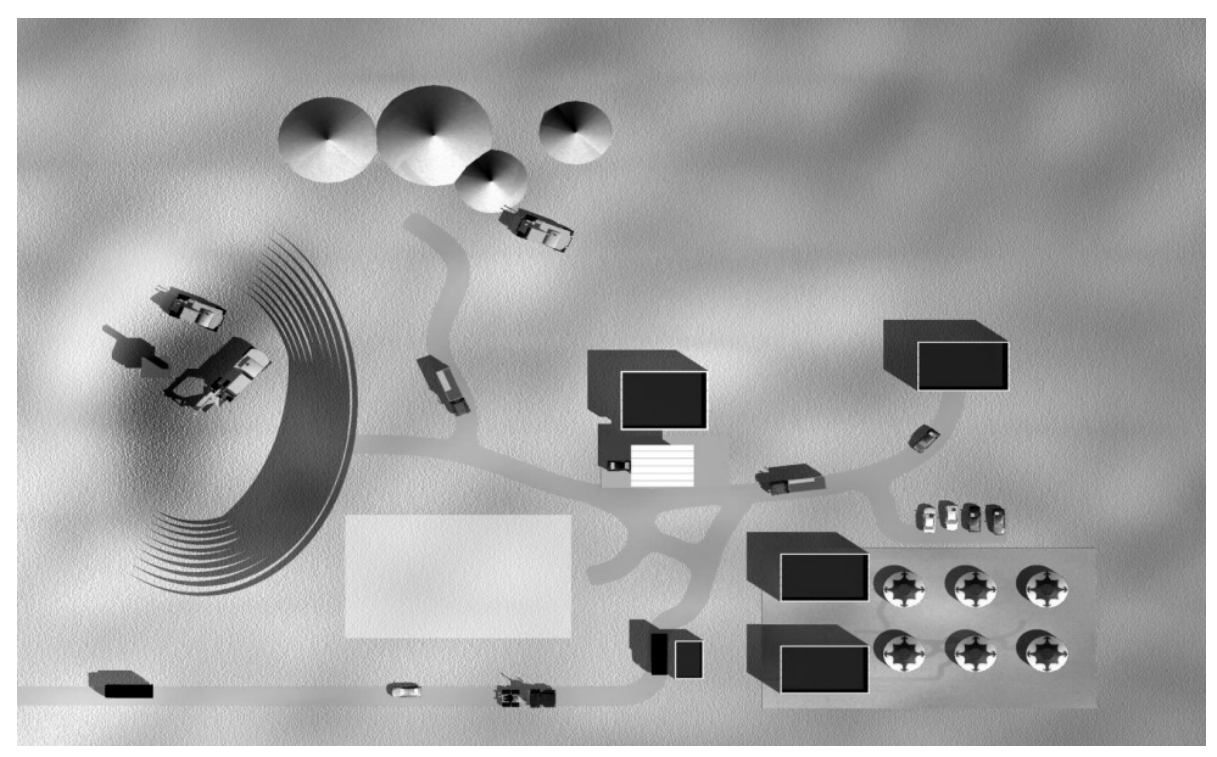

Figure 5: Animation of the MIPF.

After building the "as-is" Model, verification and validation of the model was an essential part of this path. Verification is the task of ensuring that the model behaves as you intended; more colloquially, it's known as debugging the model. Validation is the task of ensuring that the model behaves the same as the real system. In verifying the model, various obvious tests 
such as overloading the model with entities and running the model section by section was executed. The parts which revealed a vacillation was reassessed and verified repeatedly.

During the validation process the team decided to convert the model into a steady-state simulation for a realistic result. Plots of work-in-process are shown in Fig. 6.

For the warm up period, after utilizing Arena Output Analyzer, the effect of the emptyand-idle initial conditions for the first several hundred minutes on work in process is reasonably consistent across replications, but looks as if things settle down after about 3000 minutes. Thus, in order to select a more reliable option, 4800 minutes (5 days) was selected as the warm up period.

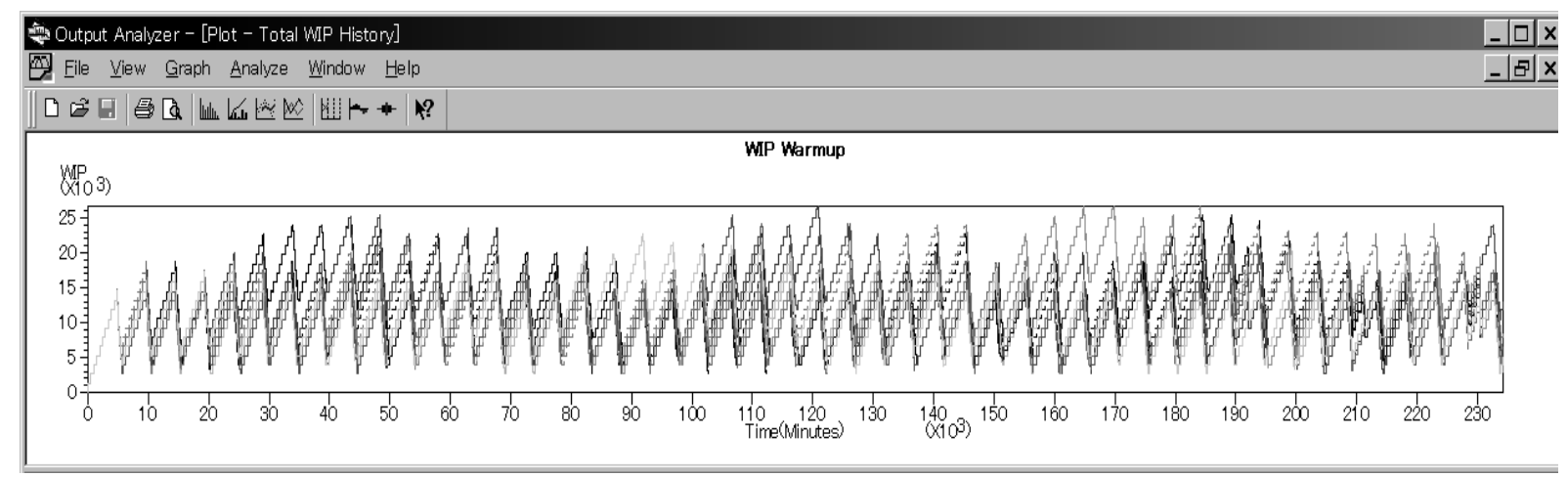

Figure 6: Work in Process Plots.

Validation was performed by comparing the replication results with the real time data of the Ervei Khuder MIPF. For example, the processed output amount of the iron and soil quantity matched the yearly production quantity of the MIPF with a difference under $1 \%$ for each replication. Furthermore, the PLT of the mining section and iron production factory section of the model matched with the average PLT of the real process, which had been acquired during the investigations from the site visits to the MIPF. This illustrates that the models' certainty and further analysis of the MIPF operation can proceed consistently.

\subsection{Analysis Results}

The team had an effective chance to observe and study the plant operation through the "as-is" model and the reports provided by the simulation analysis, which helped to find elements in the system that needed improvement. Therefore, in the study, risks from the uncertain optimization elements (R-9) were reduced due to use of simulation analysis tool.

The metrics used to measure the process is decided by the team based on the correlation with the objectives of the project. The PLT, the non value added times (waiting times), the truck utilization amount and the total number of outputs were selected as the main metrics to monitor the project progress towards the project goals which have been set in the beginning of the project.

The "as-is" model was replicated 50 times and the main metrics were obtained and analyzed by the project team. The management and the head engineers of Monzol brainstormed regarding the optimization points based on the replication reports. The following options were decided as the most favourable optimization decisions:

- To evaluate the numbers of drillers and explosion process as a variable to find results for reducing the bottlenecks and discover possibilities of additional production.

- To reduce cost, the number of trucks could be reduced to an appropriate quantity by changing the truck capacity into 40-ton Autosamosval instead of 25-ton 
Autosamosvals. The monthly rent price of 40-ton Autosamosval in USD was $\$ 2500$ compared to USD $\$ 2000$ for the 25-ton Autosamosval.

- Furthermore, if the Autosamosval capacity will be changed into a 40-ton, the load time will be increased and create another bottleneck. Therefore, to refrain from that bottleneck, an increase of the loader quantity was preferred.

The improvement points has been applied to and experimented in the simulation "to-be" model. The truck quantity was selected based on the data in Fig. 7. The main metrics assisted to choose the suitable number of trucks were the Non-Value Added Time (NVAT) of the entity waiting for transportation, which is addressed as the queue time, and the costs and the utilization amount was considered. Seven trucks were decided as the suitable quantity of the Autosamosval based on the intersection of two dimensions (cost and NVAT) in Fig. 7. The utilization amounts of seven Autosamosvals were considerably reasonable.

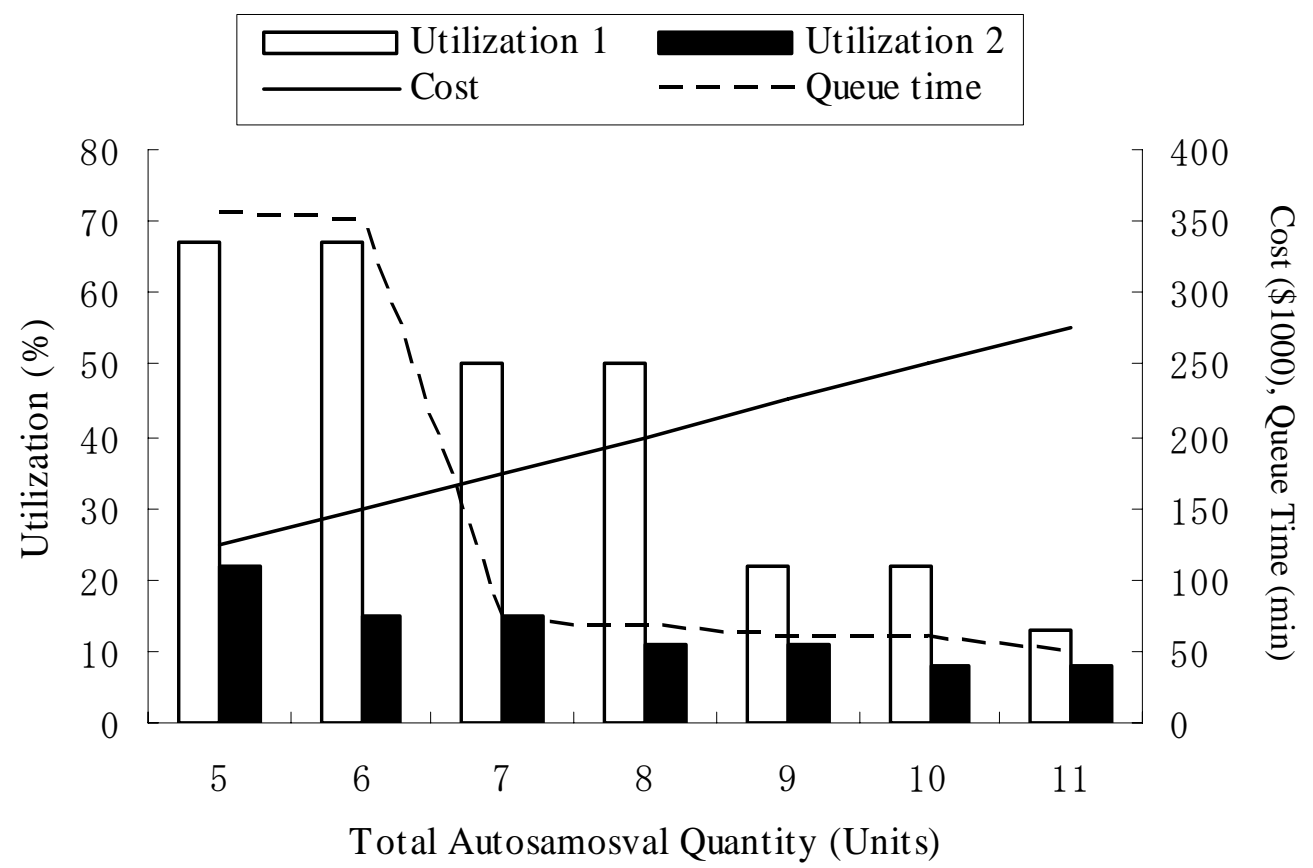

Figure 7: Variables of the Autosamosval Quantity.

Simulations are mathematical representations of scenarios involving key project risks. This might include an equation that specifies what happens to an information technology scheme when its capacity is challenged by demand, e.g., different number of machines, shut downs, and the like [14].

Based on the reports of replications with altered parameters, the best performance possibility was selected. The report summary of the replications with best possible parameters had been studied by Table III.

The NVAT, total wait time was reduced dramatically by approximately seven times, bringing the total process time down to only over 1300 minutes. Furthermore, in "to-be" 3 Model, the input was doubled to investigate the changes may occur in the model. The output increase did not cause much of a change to the PLT. Thus, the output which was doubled will evidently result a doubled profit.

According to Table III, clearly the "to-be" 3 Model shows the best possible results. Based on the "to-be" 3 Model, the bottlenecks of the process were reduced diminishing the PLT by an approximate average of 72 percent and the production doubled augmenting profit by approximately 100 percent. 
Table III: Report Summary (All Models).

\begin{tabular}{|c|c|c|c|c|c|c|}
\hline & & \multicolumn{2}{|c|}{ Entity Time (Avg) } & \multirow{2}{*}{$\begin{array}{l}\text { Queue } \\
\text { Time }\end{array}$} & \multirow{2}{*}{ Utilization (\%) } & \multirow{2}{*}{$\begin{array}{l}\text { Output } \\
\text { (Iron in tn) }\end{array}$} \\
\hline & Value & Wait Time & Total Time & & & \\
\hline \multicolumn{7}{|l|}{ "as-is" Model } \\
\hline Explosion & 1 & $3,824.78$ & 4,284.24 & $2,260.08$ & - & \multirow{3}{*}{$305,788.00$} \\
\hline 40 tn Autosamosval & 18 & - & - & 401.58 & 18 and 6 & \\
\hline Driller & 1 & - & - & $1,015.79$ & - & \\
\hline \multicolumn{7}{|l|}{ "to-be" Model } \\
\hline Explosion & 2 & $1,017.22$ & $2,478.11$ & $1,068.99$ & - & \multirow{3}{*}{$308,610.22$} \\
\hline 40 tn Autosamosval & 3 & - & - & 607.66 & 50 and 22 & \\
\hline Driller & 4 & - & - & 7.88 & - & \\
\hline \multicolumn{7}{|l|}{ "to-be" 1 Model } \\
\hline Explosion & 3 & 688.23 & $1,792.14$ & 766.80 & - & \multirow{3}{*}{$308,775.78$} \\
\hline 40 tn Autosamosval & 5 & - & - & 282.65 & 33 and 11 & \\
\hline Driller & 4 & - & - & 9.72 & - & \\
\hline \multicolumn{7}{|l|}{ "to-be" 2 Model } \\
\hline Explosion & 5 & 472.15 & $1,315.60$ & 432.23 & - & \multirow{3}{*}{$308,783.50$} \\
\hline 40 tn Autosamosval & 5 & - & - & 179.58 & 33 and 11 & \\
\hline Driller & 4 & - & - & 13.22 & - & \\
\hline \multicolumn{7}{|c|}{ "to-be" 3 Model (Input increased) } \\
\hline Explosion & 5 & \begin{tabular}{|r|}
487.45 \\
\end{tabular} & $1,346.78$ & 431.40 & - & \multirow{3}{*}{$617,949.06$} \\
\hline 40 tn Autosamosval & 5 & - & - & 345.15 & 67 and 22 & \\
\hline Driller & 4 & - & - & 39.87 & - & \\
\hline
\end{tabular}

Based on the reports of replications with altered parameters, the best performance possibility was selected. A simulation model clarified the optimization points, which reduced the risks from uncertain optimization indication (R-10).

With the outcomes of the simulation model and optimization, the management the team prepared for full scale deployment. The process ran relatively smooth but further optimization may be required in the future.

Risk management is most effective when it is done and redone as an integral part of normal project planning and management [15]. Thus the team needs to monitor frequently the implementation of the above optimization points of the MIPF as part of the project.

\section{CONCLUSIONS}

1. Computer aided simulation analysis was used to examine number of different scenarios with varied quantity of trucks and drillers and altered number of explosion process. Based on the replication reports of the simulation analysis, the best scenario was chosen by the team. Consequently, the team has met the project goals. The team provided an increased profitability due to increased capacity with an escalated output, diminished bottlenecks reducing the PLT and as an outcome of the previous two results, apparently, the cost was reduced.

2. Simulation analysis software has provided a clearer view of the process and created a virtual reality of the possible scenarios that helped the team to be confident in their optimization points. This can reduce the uncertainty risks.

3. An accurate replication report of the simulation analysis, such as the NVAT, utilization percentage, and total time, has given the ability to precisely compare the scenarios and select the best possible scenario. 
4. The use of simulation analysis tool has given the team a certainty of elements required an optimization and indication on how to optimize those elements. Furthermore, one of the risks of the management feared was a process interruption for this optimization project, which may have resulted in idle time costs. As a result of the simulation analysis tool, the project team had a satisfactory virtual model of the system, provided an opportunity to create various scenarios with optimization points and alter the model as they wish without any fear from negative risk factors.

5. The management has pointed out that, risks from machinery break down, delays from repair work can be considered in the future optimization projects. Furthermore, the team can investigate the possibility of calculating delays may occur from irresponsibility of the workers, poor management, accidents and other risks from human/organizational resistance.

\section{REFERENCES}

[1] Cooper, D.; Grey, S.; Raymond, G.; Walker, P. (2005). Project Risk Management Guidelines: Managing Risk in Large Projects and Complex Procurements, John Wiley \& Sons Ltd, Chichester

[2] Shannon, R. E. (1998). Introduction to the art and science of simulation, Proceedings of the 1998 Winter Simulation Conference, 7-14

[3] Del Cano, A.; de la Cruz, M. P. (2002). Integrated methodology for project risk management, Journal of Construction Engineering and Management, Vol. 128, No. 6, 473-485

[4] Williams, T. (1995). A classified bibliography of recent research relating to project risk management, European Journal of Operational Research, Vol. 85, 18-38

[5] Baker, R. W. (1986). Handling uncertainty, International Journal of Project Management, Vol. 4, No. 4, 205-210

[6] Hall, J. N. (1986). Use of risk analysis in North Sea projects, International Journal of Project Management, Vol. 4, No. 4, 217-222

[7] Clark, P.; Chapman, C. B. (1987). The development of computer software for risk analysis: A decision support system development study, European Journal of Operational Research, Vol. 29, 252-261

[8] Coelho, D. K.; Jacinto, C. M. C. (2005). Risk assessment of drilling and completion operations in petroleum wells using a Monte Carlo and a neural network approach, Proceedings of the 2005 Winter Simulation Conference, 1892-1897

[9] Jacinto, C. M. C. (2002). Discrete event simulation for the risk of development of an oil field, Proceedings of the 2002 Winter Simulation Conference, 1588-1592

[10] Lyons, T.; Skitmore, M. (2004). Project risk management in the Queensland engineering construction industry: a survey, International Journal of Project Management, Vol. 22, No 1, 5161

[11] El-Sayegh, S. M. (2008). Risk assessment and allocation in the UAE construction industry, International Journal of Project Management, Vol. 26, 431-438

[12] Kelton, D.; Sadowski, R.; Sturrock, D. (2007). Simulation with Arena, Fourth Edition, McGraw Hill, Inc., New York

[13] Luce, K.; Trepanier, L.; Ciochetto, F.; Goldman, L. (2005). Simulation and optimization as effective DFSS tools, Proceedings of the 2005 Winter Simulation Conference, 1993-1999

[14] Bowers, J. (1994). Data for project risk analyses, International Journal of Project Management, Vol. 12, No. 1, 9-16

[15] Gardiner, P. D. (2005). Project Management: A Strategic Planning Approach, Palgrave Macmillan, New York 